\title{
Labor in the food system: A view from INFAS
}

Joanna Friesner,* INFAS National Network Coordinator, with contributions from the INFAS co-creators of the Statement on Equity in the Food System (see list below)

The Inter-institutional Network for Food, Agriculture and Sustainability (INFAS or "the Network"), initiated informally in 2008 and formalized in 2011, encompasses a broad group of practitioners, primarily in academic institutions, who work individually on a diverse range of topics in agricultural and food system sustainability. INFAS grew from a shared vision to expose the challenges facing the transformation of agriculture and our global food system, including the sometimes competing interests of labor, producers, and consumers in the food system. From the start, the Network was envisioned to include activists in collaboration with academics in order to broadly improve the economic, environmental, and social sustainability of the food system by spanning disciplinary and institutional boundaries, convening diverse stakeholders, and linking knowledge with action. We envision an environmentally sustainable and socially just U.S. food system. This requires that race, class, and gender no longer determine health

* Joanna Friesner, INFAS Coordinator, Agricultural Sustainability Institute; One Shields Drive; University of California, Davis; Davis, California 95616 USA: jdfriesner@ucdavis.edu outcomes, social status, or economic opportunity, and that healthy, restored agroecosystems and fisheries are achievable.

The topic of "Labor in the Food System from Farm to Table" aligns with the Network's mission and values, and thus we are honored to support this special issue of the Journal of Agriculture, Food Systems, and Community Development (JAFSCD). Food system workers make up a large part of the U.S. workforce, yet often face a multitude of barriers and injustices, including low wages, unreliable and unsafe working conditions, and poor benefits and legal protections. Patricia Allen, an INFAS participant, has contributed the issue overview editorial that reflects on labor in the food system, weaving in the key themes of the individual journal contributors. We applaud all the contributors whose work is included in this issue and who strive to illuminate the specific and interconnected challenges facing labor in the food system.

INFAS has reexamined the core focus for our collective action, especially given the barriers inherent to a dispersed volunteer network whose members are deeply engaged in a broad spectrum of sustainability, agriculture, and food system 
challenges. We have concluded that we must focus on historical and institutional barriers that constrain food system sustainability. We realize that the challenge, and the opportunity, presented to a network such as ours is finding ways to collaborate on a wicked and thorny issue that will requires all of us to move together toward change. INFAS was created to pursue issues that span boundaries in discourse and practice and can not be solved by any one person. In short, social justice and racial equity in the food system have emerged as key issues that bring us together.

As a Network, we:

- See that food and agriculture are part of a diverse set of interconnected systems. We recognize the value of systemic analysis in identifying the impacts of policies and practices; how components of the food system function; and gaps in our understanding. We recognize that the food system affects and is affected by almost every other sphere of human activity and well-being. Therefore, we value transdisciplinary and interdisciplinary approaches to solving problems, in addition to contributions that are made within single disciplines.

- Recognize that the global food system is profoundly inequitable with respect to gender, class, and race. In the U.S., racial inequity is expressed by the legacies of slavery, racism, and theft of resources from indigenous peoples, all of which continue to prevent equal opportunity for many individuals and groups. Inequity is also expressed structurally in the leadership, infrastructure, and decision-making mechanisms of our food system, which continues to favor the subset of the population that has held power in the U.S. from its founding as a country (usually white, male, and from a background of relative affluence).

- Value the cultural diversity of the U.S. food system embodied in the many foodways and cultural practices of all our peoples. We understand that food production and food consumption have spiritual, cultural, and social significance that goes far beyond food's nutritional and economic value.

- Recognize multiple converging trends in U.S. food systems that lead us away from sustainability, resilience, and social equity and instead toward irreversible thresholds which could drastically transform our world. We know that we live in a time of increasing uncertainty that demands new coping mechanisms. Global environmental change (e.g., climate change, nutrient-cycle disruption, loss of biodiversity, and ocean acidification) constitutes a cluster of potentially severe thresholds to which food systems contribute. Strikingly, the loss of human diversity, as indigenous peoples and their languages continue to be decimated, also is irreversible.

- See that public policies and practices sometimes push food system actors away from sustainability, resilience, and social equity. We understand that these policies and practices have global impacts, affecting the food system choices of people across the world as well as within our own borders, and leading to limits on opportunities for all, especially women, poor people, and people of color. We know that policies and practices can be changed with sufficient motivation, knowledge, and mobilization of political power.

- Seek to meet our responsibilities as food citizens from our positions within, or working with, institutions of higher education. We understand that the goal of sustainability is a call to action that requires much more of us than what is found in our formal job descriptions, and we come together to learn and to act in more effective ways to promote racial equity, economic equity, and environmental restoration and health.

Several INFAS participants ${ }^{\dagger}$ developed the INFAS Statement on Equity in the Food System to underpin our Network's mission, guide our collective action, and explain our values: 
1. INFAS is a network of educators and researchers who are dedicated to all aspects of food system sustainability and are committed to supporting, learning from, and partnering with activists in our communities. We recognize that our food system is profoundly inequitable, and that institutions of higher education hold power and privilege that can be used for good or harm. Equity in opportunity, food access, and health outcomes are non-negotiable and foundational principles of a sustainable food system, and core values and commitments for us.

2. To help build equity in the food system, we focus on the barrier of structural racism. We recognize multiple forms of oppression, and so we also focus on gender and class oppression and the intersections among race, class, and gender that shape barriers and opportunities to equity.

3. We make a commitment to collaborate with communities of practice. Our research, education, and convening capabilities help us understand, communicate, and find solutions to how food system disparity mirrors systemic inequities. We strive to work with and respect community members as leaders, co-creators of knowledge, co-formulators of questions, and co-facilitators in building solutions as we endeavor to create a more just food system for all people.

This statement is intended to simultaneously acknowledge the multidimensionality of the U.S. food system and reinforce that INFAS values

† The following are INFAS co-creators of the Statement on Equity in the Food System:

Casey Hoy, The Ohio State University

Cheryl Danley, Independent consultant, food systems and sustainable development

Curtis Ogden, Interaction Institute for Social Change

Joann Lo, Food Chain Workers Alliance

Joanna Friesner, University of California, Davis systemic analyses and transdisciplinary, interdisciplinary, and single-discipline approaches to solving problems. Rather than establish an either/or scenario where the Network focuses on the science and practice of environmental or economic or social sustainability in the food system, INFAS participants commit to work on all three pillars of sustainability in order to improve agricultural and food system resilience. We recognize that structural racism and gender and class oppression-and the intersections among these-within the U.S. food system are systemwide impediments to sustainability.

In concert with many other efforts, the Network's collaborative work can help to legitimize a discourse that addresses social justice and the myriad interconnected environmental and economic challenges in the U.S. food system. We believe that many complex and embedded issues have produced the system. These issues may be invisible to many, but must be addressed to effect meaningful change. The discussions that culminated in the development of our vision and equity statement have been difficult but essential to challenging - and ultimately transforming - the current system into one that is sustainable, equitable, and resilient for all. We commit to continuing to engage in difficult conversations within our institutions and the Network, and to reaching out to a broad set of stakeholders, both within and beyond academia. Ideally, we want INFAS to be an inclusive group achieving necessary goals for sustainable U.S. food systems that we cannot achieve as individuals. For information on collaborative opportunities, we invite you to visit http://asi.ucdavis. edu/networks/infas/join-infas.

John O'Sullivan, North Carolina A\&T State University (Emeritus)

Molly Anderson, Middlebury College

Patricia Allen, Marylhurst University

Shorlette Ammons, North Carolina A\&T State

University (Center for Environmental Farming Systems)

Tom Kelly, University of New Hampshire

Tom Tomich, University of California, Davis 